\title{
High-pressure high-temperature stability and thermal equation of state of zircon-type erbium vanadate
}

Javier Ruiz-Fuertes ${ }^{1, *}$, Domingo Martínez-García², Tomás Marqueño², Daniel Errandonea ${ }^{2}$, Simon G. MacLeod ${ }^{3,4}$, Thomas Bernert ${ }^{5}$, Eiken Haussühl ${ }^{6}$, David Santamaría-Pérez ${ }^{2}$, Jordi Ibáñez $^{7}$, Anitha Mallavarapu ${ }^{8}$, S. Nagabhusan Achary ${ }^{9}$, Catalin Popescu ${ }^{10}$, and Marco Bettinelli ${ }^{11}$

1. DCITIMAC, Universidad de Cantabria, Avenida Los Castros 48, 39005 Santander, Spain

2. Departament de Física Aplicada, Universitat de València, Dr. Moliner 50, 46100 Burjassot, Spain

3. Atomic Weapons Establishment, Aldermaston, Reading RG7 4PR, United Kingdom

4. SUPA, School of Physics \& Astronomy, and Centre for Science at Extreme Conditions, The University of Edinburgh, Edinburgh, EH9 3FD, United Kingdom

5. Max-Planck-Institutfür Kohlenforschung, Kaiser-Wilhelm-Platz 1, 45470 Mülheim an der Ruhr, Germany

6. Institut für Geowissenshaften, Goethe-Universität Frankfurt, Altenhöferallee 1, 60438 Frankfurt am Main, Germany

7. Institute of Earth Sciences Jaume Almera, CSIC, 08028 Barcelona, Spain

8. Material Processing \& Corrosion Engineering Division, Bhabha Atomic Research Centre, Trombay, Mumbai 400085, India

9. Chemistry Division, Bhabha Atomic Research Centre, Trombay, Mumbai 400085, India

10. CELLS-ALBA Synchrotron Light Facility, 08290 Cerdanyola del Vallés, Barcelona, Spain

11. Laboratorio Materiali Luminescenti, DB, Università di Verona, and INSTM, UdR Verona, 37134 Verona,Italy

\begin{abstract}
The zircon to scheelite phase boundary of $\mathrm{ErVO}_{4}$ has been studied by highpressure and high temperature powder and single crystal x-ray diffraction. This study has allowed us to delimit the best synthesis conditions of its scheelite-type phase, determine the ambient temperature equation of state of the zircon and scheelite-type structures, and obtain the thermal equation of state of the zircon-type polymorph. The results obtained with powder samples indicate that zircon-type $\mathrm{ErVO}_{4}$ transforms to scheelite at 8.2 GPa and $293 \mathrm{~K}$, and at $7.5 \mathrm{GPa}$ and $693 \mathrm{~K}$. The analyses yield bulk moduli $K_{0}$ of 158(13) GPa for the zircon phase and 158(17) GPa for the scheelite phase, with a temperature derivative of $\mathrm{d} K_{0} / \mathrm{d} T=-3.8(2) \times 10^{-3} \mathrm{GPa} \mathrm{K}^{-1}$ and a volumetric thermal expansion of $\alpha_{0}=$ $0.9(2) \times 10^{-5} \mathrm{~K}^{-1}$ for the zircon phase according to Berman model. The results are compared with those of other zircon-type vanadates raising the need of careful experiments with highly crystalline scheelite to obtain reliable bulk moduli of this phase. Finally, we have performed single crystal diffraction experiments from $110 \mathrm{~K}$ to $395 \mathrm{~K}$ and the obtained volumetric thermal expansion $\left(\alpha_{0}\right)$ for zircon-type $\mathrm{ErVO}_{4}$ in the 300-395 $\mathrm{K}$ range is $1.4(2) \times 10^{-5} \mathrm{~K}^{-1}$ in good agreement with previous data and with our experimental value given from the thermal equation of state fit within the limits of uncertainties.
\end{abstract}

*email: ruizfuertesj@unican.es 


\section{Introduction}

Pure or doped vanadates containing a rare-earth $(R)$ cation crystallize in the zircon-type structure (tetragonal, space group $14 \mathrm{l} /$ amd, No. 141) and are excellent host systems for the development of applications as thermophosphors, scintillators, lasers, or sensors in drug delivery ${ }^{1,2,3}$. In this structure the $R$ atom is coordinated by $8 \mathrm{O}$ atoms while $\mathrm{V}$ is tetrahedrally coordinated. The crystal structure consists of a chain of alternating edge-sharing $\mathrm{VO}_{4}$ tetrahedra and $\mathrm{RO}_{8}$ dodecahedra extended parallel to the $c$ axis.

The growth of vanadates as well as the development for applications based on these compounds makes the accurate determination of their phase diagram and hightemperature equation of state (EOS) crucial. Zircon-type vanadates undergo in most cases an irreversible phase transition ${ }^{4}$ to a scheelite-type structure (tetragonal, space group $I 4_{\mathrm{l}} / a$, No. 88) at moderate pressures. In the well-known $\mathrm{YVO}_{4}{ }^{5}$ this phase transition takes place at 7.5 GPa. Even though the scheelite-type structure does not differ much from the zircon-type structure with both keeping the same coordination scheme, the transformation involves a unit-cell volume collapse of around 10\% that compromises the crystallinity of the scheelite-type phase when the transformation is induced at room temperature. To overcome this drawback, the phase transition can be induced at high pressure and high temperature. There are a few studies dealing with the zircon-scheelite pressure-induced transformation at high temperature of different materials ${ }^{6}$, and the pressure and temperature conditions for the synthesis of $\mathrm{ErVO}_{4}$ reported by Range and Meister ${ }^{7}$ is one of the examples. However, a systematic study on the phase boundaries and thermal properties of the zircon phase is still lacking in literature. In the case of $\mathrm{ErVO}_{4}$ the onset of the phase transition at room temperature and its change with pressure is unknown and the only information reported ${ }^{7}$ is that scheelite-type $\mathrm{ErVO}_{4}$ can be obtained at $4 \mathrm{GPa}$ in the $1000 \mathrm{~K}$ to $1525 \mathrm{~K}$ temperature range. However, in a previous work, Shin-ike et al. ${ }^{8}$ 
showed that at $1673 \mathrm{~K}, \mathrm{Er}_{2} \mathrm{O}_{3}$ and $\mathrm{VO}_{2}$ react to vanadium reduced calcite (3 $\mathrm{GPa}$ ) and vaterite (5 GPa), while at the same temperature and pressures $\mathrm{Er}_{2} \mathrm{O}_{3}$ and $\mathrm{V}_{2} \mathrm{O}_{3}$ react to perovskite-type $\mathrm{ErVO}_{3}$. This indicates that the zircon-type to scheelite-type transformation range at high temperature is extremely narrow and still remains unclear. Here we present in situ high pressure and room temperature single crystal and powder xray diffraction (XRD) and high-pressure and high-temperature powder XRD studies with a diamond anvil cell up to $20 \mathrm{GPa}$ and $700 \mathrm{~K}$, as well as an ex situ powder XRD study with a Paris-Edinburgh cell at 4 GPa and temperatures up to 1070(10) K.

\section{Experimental details}

Powder sample of $\mathrm{ErVO}_{4}$ was prepared by a conventional solid-state reaction of $\mathrm{Er}_{2} \mathrm{O}_{3}$ and $\mathrm{V}_{2} \mathrm{O}_{5}$. Prior to use, $\mathrm{Er}_{2} \mathrm{O}_{3}$ (Johnson Matthey, $99.99 \%$ ) and $\mathrm{V}_{2} \mathrm{O}_{5}$ (Riedel-de Haën, $99.5 \%$ ) were heated at $1073 \mathrm{~K}$ (for 12h) and $673 \mathrm{~K}$ (for 8 h), respectively. Appropriate amounts of preheated $\mathrm{Er}_{2} \mathrm{O}_{3}$ and $\mathrm{V}_{2} \mathrm{O}_{5}$ for $10 \mathrm{~g}$ of $\mathrm{ErVO}_{4}$ composition were mixed thoroughly in acetone media and dried at room temperature. The homogenous mixture was pressed into a pellet of (diameter 25mm), then heated slowly to $1023 \mathrm{~K}$ and soaked while it was kept at that temperature for about $12 \mathrm{~h}$. Complete formation of zircon type $\mathrm{ErVO}_{4}$ was observed. The obtained product was homogenized and pelletized, and again heated at $1273 \mathrm{~K}$ for another $12 \mathrm{~h}$. Bright pink coloured product obtained after this heat treatment was characterized by powder XRD using $\mathrm{Cu} K_{\alpha}$ radiation and then used for further studies.

Single crystals of $\mathrm{ErVO}_{4}$ with the zircon-type structure were grown using the flux method $^{9}$. This method is based on the same techniques employed for the synthesis and growth of rare-earth orthophosphate $\left(\mathrm{RPO}_{4}\right)$ and orthoarsenate $\left(\mathrm{RAsO}_{4}\right)$ single crystals from molten salt solutions. The procedure involves the dissolution of the rare-earth oxide, 
$\mathrm{Er}_{2} \mathrm{O}_{3}$ in molten $\mathrm{Pb}_{2} \mathrm{~V}_{2} \mathrm{O}_{7}$ at high temperature, with spontaneous nucleation and crystal growth of $\mathrm{ErVO}_{4}$, achieved by slow cooling of the solution.

The high-pressure and high-temperature synthesis of the scheelite phase of $\mathrm{ErVO}_{4}$ was carried out in a Paris-Edinburgh press setup equipped with two opposed conical tungsten-carbide anvils. Boron nitride acted as the pressure-transmitting medium for a compacted powder sample of zircon-type $\mathrm{ErVO}_{4}$. An outer small graphite tube containing the boron nitride cylinder was used as the heating element. Two molybdenum discs, placed on the bases of the graphite oven, acted as the electrodes for the heating system. The sample assembly was introduced into a fired pyrophyllite gasket (treated previously at $1223 \mathrm{~K}$ for 1 hour and $30 \mathrm{~min}$ ). A teflon ring was added around the gasket to limit the lateral extrusion during compression and to increase the pressure-load efficiency. The oil pressure in the ramp was raised by using a simple hand-operated hydraulic pump. The sample was heated by applying a DC current across the graphite furnace, using a computer-controlled power supply. Pressure and temperature, respectively, were determined by load-applied and power-temperature calibration curves with experimental error estimated to be less than 5\%. The preparation of scheelite-type $\mathrm{ErVO}_{4}$ was performed at a pressure of $\sim 4 \mathrm{GPa}$ and at temperatures from $670(10) \mathrm{K}$ to $1270(10) \mathrm{K}$. The pressure upstroke was performed in two steps with a 2 minutes plateau at $~ 2 \mathrm{GPa}$. After reaching the target pressure, the temperature was increased linearly from room temperature to the final temperature for ten minutes and then kept at the maximum value for half an hour. A rapid thermal quench was performed afterwards. Finally, the pressure was released in few hours and the sample was then recovered to ambient conditions. The product was characterized ex situ with powder XRD (PXRD) performed at room temperature on a Bruker D8 Advance diffractometer in Bragg-Brentano configuration by using $\mathrm{Cu} K_{\alpha}$ radiation. The diffractograms were refined with the Rietveld method using 
the program GSAS ${ }^{10,11}$ in order to quantify the amount of scheelite synthesized after each run.

The high-pressure single crystal XRD (SXRD) experiment was performed with a Boehler-Almax diamond anvil cell (DAC) $\left(4 \theta \sim 70^{\circ}\right)$ in which a $10-\mu m$-thick single crystal was introduced inside a $150 \mu \mathrm{m}$ diameter hole of a W gasket preindented to 40 $\mu \mathrm{m}$. The pressure calibrant was a ruby chip ${ }^{12}$ and the pressure transmitting medium was Ne which is fluid up to $4.7 \mathrm{GPa}^{13}$ and assures a quasi-hydrostatic environment up to 15 $\mathrm{GPa}^{4}$. This experiment was done at the Extreme Conditions beamline at PETRA III with a wavelength of $\lambda=0.29036 \AA$ focused to $3 \times 8 \mu \mathrm{m}^{2}$ (FWHM) with compound refractive lenses (CRL) and using a PerkinElmer detector placed $415.5 \mathrm{~mm}$ from the sample. The diffraction images were collected by $0.5^{\circ} \omega$ scanning. The image format was converted according to the procedure described by Rothkirch et al. ${ }^{15}$ and indexing reflections and intensity data reduction were carried out by CRYSALIS ${ }^{\text {Pro }}$ software $^{16}$. The structures were refined with SHELX-97-2 ${ }^{17}$.

The ambient temperature and high pressure PXRD experiments with the zircon and scheelite-type polymorphs were also carried out with Boehler-Almax DACs. In this case, the experiments were performed at the MSPD beamline at ALBA-CELLS synchrotron with a wavelength of $\lambda=0.4246 \AA$ and $\lambda=0.5230 \AA$, respectively. The $\mathrm{x}-$ ray beam was focused down to $\sim 20 \times 20 \mu \mathrm{m}^{2}$ in both cases and a Rayonix CCD detector was used for data collection. In these two cases, the gasket was stainless-steel preindented to $40 \mu \mathrm{m}$ with a hole of $200 \mu \mathrm{m}$ and the pressure sensor was a ruby chip ${ }^{12}$. A 4:1 mixture of methanol-ethanol was used as pressure transmitting medium ${ }^{14,18}$ in both experiments. The images obtained with the CCD were integrated with the program DIOPTAS and the lattice parameters were obtained with the UNITCELL program $^{19}$. 
The high-temperature PXRD experiments were carried out also at ALBA-CELLS using a wavelength of $\lambda=0.4246 \AA$. In this case membrane-type DACs were placed inside a custom-built vacuum vessel designed for high-pressure and high-temperature experiments $^{20,21}$. The DACs were heated using Watlow $240 \mathrm{~V}$ coiled heaters wrapped around it. The temperature was measured using a K-type thermocouple attached to one of the diamond anvils, close to the gasket. $\mathrm{NaCl}$ was used as pressure transmitting medium and pressure calibrant according to ${ }^{22}$. The lattice parameters were obtained with the UNITCELL program ${ }^{19}$.

Single crystal XRD data were collected at 110(3), 205(3), 298(3), and 395(3) K, using an Xcalibur3 k-circle diffractometer from Oxford diffraction with a CCD camera and molybdenum (Mo) Ka radiation from a Mo anode operating at $45 \mathrm{kV}$ and $38 \mathrm{~mA}$. The Xcalibur is equipped with a cryostream system (cryojet HT Oxford diffraction), stabilizing the sample temperature within $\pm 2 \mathrm{~K}$.

\section{Sample characterization and synthesis of scheelite-type ErVO 4}

Scheelite-type $\mathrm{ErVO}_{4}$ can be produced phase impure from its constituents $\mathrm{Er}_{2} \mathrm{O}_{3}$ and $\mathrm{V}_{2} \mathrm{O}_{5}$ after milling in a planetary ball milling for 480 minutes $^{23}$. However, this route does not provide a highly crystalline powder since in this process the size of the crystal grains is critically reduced and also undue strains are introduced in the lattice. Therefore, this approach is not appropriate to obtain highly crystalline scheelite-type $\mathrm{ErVO}_{4}$. Phase pure and highly crystalline scheelite-type phase of $\mathrm{ErVO}_{4}$ was first synthesized by Range and Meisner ${ }^{7}$ after subjecting the powder sample of zircon-type $\mathrm{ErVO}_{4}$ to simultaneous temperature (1525 K) and pressure (4 GPa). In that study it was established a range from 1000 to $1525 \mathrm{~K}$ in which such a transformation would occur. However, when we tried to reproduce the experiment at $1070(10) \mathrm{K}$ to obtain highly crystalline scheelite-type $\mathrm{ErVO}_{4}$ 
it was found in addition to scheelite-type $\mathrm{ErVO}_{4}$ a considerable amount of reduced perovskite-type $\mathrm{ErVO}_{3}$ (S. G. Pbnm) and pyrochlore-type $\mathrm{Er}_{2} \mathrm{~V}_{2} \mathrm{O}_{7}$ (S. G. Fd3m) (Fig. 1), not reported by Range and Meisner ${ }^{7}$; as the result of a reduction of $\mathrm{V}^{5+}$ to $\mathrm{V}^{4+}$ and $\mathrm{V}^{3+}$ probably due to the graphite or the molybdenum employed in the high-pressure and hightemperature synthesis. This synthesis result motivated us to perform a systematic study on synthesis of scheelite type $\mathrm{ErVO}_{4}$, and on the effect of pressure and/or temperature on scheelite and zircon type $\mathrm{ErVO}_{4}$. We performed five syntheses at 670(10), 770(10), 870(10), 970(10), and 1070(10) K, maintaining the pressure at 4 GPa. The diffraction patterns of the products are shown in Fig. 1 (a) and (b) together with the pattern of the starting zircon-type $\mathrm{ErVO}_{4}$ at $300 \mathrm{~K}$. The purity of the starting zircon-type $\mathrm{ErVO}_{4}$ is confirmed by the indexation of all the observed reflections to the zircon-type tetragonal structure of $\mathrm{ErVO}_{4}$. After the synthesis at $670(10) \mathrm{K}$ some scheelite weak reflections emerge (9 wt\%, as obtained with a Rietveld quantitative phase analysis). This temperature is still too low to thermally anneal the powder but is enough to start transforming zircontype $\mathrm{ErVO}_{4}$ into its scheelite phase. Thus, the XRD scan of the zircon phase after being submitted to these conditions exhibits broad reflections that could be due either to poor crystalline quality or an increase of the density of defects as we shall comment below. After the synthesis at $770(10) \mathrm{K}$ the pattern continues being broad but the scheelite reflections are now evident (20 wt. \%). The 112 reflection of scheelite located at around $30^{\circ}$ with $\mathrm{Cu}-\mathrm{K}$ radiation is clearly visible. At $870(10) \mathrm{K}$ the scheelite-type phase already dominates (79 wt. \%), and the reflections appear much narrower than at lower temperatures due to the annealing effect of temperature. At 970(10) K we obtained almost phase-pure scheelite-type $\mathrm{ErVO}_{4}$ (94 wt. \%) with only 6 wt.\% of zircon-type $\mathrm{ErVO}_{4}$ impurities and a negligible amount of perovskite type $\mathrm{ErVO}_{3}$ that could not be quantified. However, when the temperature of the synthesis is raised to $1070(10) \mathrm{K}$ the edges of the 
sintered powder were dark brown instead of pink and the intense extra reflections confirmed the presence of perovskite-type $\mathrm{ErVO}_{3}$ and pyrochlore-type $\mathrm{Er}_{2} \mathrm{~V}_{2} \mathrm{O}_{7}$, indicating the onset of the reduction of $\mathrm{V}^{5+}$ to $\mathrm{V}^{3+}$ and $\mathrm{V}^{4+}$. A possible reason causing this reduction could be the use of $\mathrm{BN}$ sleeves in combination with graphite heaters, which could have created reducing synthesis conditions favoring compounds with reduced vanadium. Such a vanadium reduction would probably cause additional effects such as an increase of the defect densities in the zircon phase which could in turn also contribute to the broadening of the reflections observed at 670(10) $\mathrm{K}$ and at higher temperatures and also to the color change.

The ambient-conditions lattice parameters and atomic coordinates obtained from Rietveld analysis are shown in Table 1 in comparison to previous data from Baglio and Sovers ${ }^{24}$ and Renge and Meister ${ }^{7}$. The agreement is good and provides $\mathrm{ErO}_{8}$ polyhedra volumes at ambient pressure of 23.44(1) $\AA^{3}$ and 23.08(1) $\AA^{3}$ for the zircon and scheelite structures, respectively.

\section{Results and discussion}

a. Ambient temperature stability and compressibility of zircon and scheelite-type $\mathrm{ErVO}_{4}$

The evolution of the powder XRD patterns of zircon-type $\mathrm{ErVO}_{4}$ up to 15.5(2)

GPa and the change of the XRD reflections of a single-crystal collected with a $20^{\circ} \omega$-scan at 8.1(1) and 9.0(1) GPa are shown in Fig. 2. At ambient pressure the XRD pattern corresponds to the zircon-type tetragonal structure (space group $14 \mathrm{l} / \mathrm{amd}$ ) and can be described with the same I4//amd space group up to 8.2(1) GPa. At this pressure all the reflections start to broaden, and an additional reflection emerges at $2 \theta \sim 8^{\circ}$. This feature, which corresponds to the 112 reflection of the scheelite-type structure of $\mathrm{ErVO}_{4}$ (space group $I 4_{1} / a$ ), sets the onset of the phase transition. As can be seen in Fig. 2, the transition 
is only completed at 15.5(2) GPa. As expected in a phase transition which involves a large volume collapse ${ }^{5}$, the phase coexistence and the loss of crystallinity of the sample contribute to a significant broadening of the reflections, preventing an accurate determination of the lattice parameters of both phases above the phase transition. The broadening of the reflections is further evidenced with the change observed in the singlecrystal frame from 8.1(1) to 9.0(1) GPa shown in Fig. 2. At 8.1(1) GPa the reflections from the sample and the reflections from the diamonds of the anvils of the DAC (highlighted in red) are perfectly rounded. However, only 0.9 GPa above, the phase transition starts and the reflections from the zircon crystal become impossible to centre. Similarly, the reflections of the scheelite phase appear too diffuse to be properly located. This implies that to study the behaviour under compression of the scheelite-type phase of $\mathrm{ErVO}_{4}$ we require a good quality sample of scheelite-type $\mathrm{ErVO}_{4}$. We have shown in previous section (Sec. 3) that the crystallinity of the scheelite phase is highly increased when the irreversible zircon-to-scheelite phase transition is induced at high temperature and then quenched (Fig. 1).

Fig. 3 shows two XRD patterns at ambient and 9.2(1) GPa of scheelite-type $\mathrm{ErVO}_{4}$ sample at obtained after a 30-min treatment on a zircon-type sample subjected to 4 GPa and 970(10) K in a Paris-Edinburgh press (Sec. 3). In this case there is no evidence of the zircon-type $\mathrm{ErVO}_{4}$ impurities observed in the experiment with Cu radiation (Fig. 1). Since the in situ powder XRD experiment was carried out using a 4:1 mixture of methanolethanol, it was terminated at 9.2(1) GPa to guarantee hydrostatic conditions ${ }^{14,18}$. No additional XRD reflections are observed up to 9.2(1) GPa, confirming the stability of scheelite-type $\mathrm{ErVO}_{4}$ at least up to this pressure.

The pressure dependence of the unit-cell of both zircon-type and scheelite-type tetragonal structures is presented in Fig. 4 and the lattice parameters, atomic coordinates, 
and acquisition and refinement parameters obtained for zircon-type $\mathrm{ErVO}_{4}$ at 6.4(1) and 8.1(1) GPa in the single-crystal XRD experiment are in Table 2. Notice that atomic positions of oxygen (the only ones not constrained by symmetry) are very similar at both pressures and agree within errors with those determined at ambient conditions by Baglio and Sovers from single-crystal XRD experiments ${ }^{24}$. Therefore, the atomic positions are apparently not affected by compression within the measurement uncertainty of this work, as happens in zircon-type phosphates ${ }^{25}$.

Among the lattice parameters, the $c$-lattice parameter of the zircon-type phase shows a larger dispersion because in zircon the information along the [00l] direction is much more reduced in the measured range in the powder XRD experiment, with no isolated $00 \mathrm{l}$ reflections observed. The lattice parameters of both structures follow a second-order Birch-Murnaghan (BM) equation of state EOS $^{26}$ which have been fitted using the EosFit-7 program ${ }^{27}$. We obtain linear compressibilities of $\kappa_{a}=2.0(1) \times 10^{-3} \mathrm{GPa}^{-}$ ${ }^{1}$ and $\kappa_{c}=1.6(2) \times 10^{-3} \mathrm{GPa}^{-1}$ for zircon-type $\mathrm{ErVO}_{4}$, and $\kappa_{a}=1.7(1) \times 10^{-3} \mathrm{GPa}^{-1}$ and $\kappa_{c}=$ 2.3(1) $\times 10^{-3} \mathrm{GPa}^{-1}$ for scheelite-type $\mathrm{ErVO}_{4}$. These values show the large incompressibility, typical of zircons, and indicate that in both phases the longest axes are also the most compressible ones. This occurs because in both structures the $\mathrm{VO}_{4}$ tetrahedra are much less compressible than the $\mathrm{ErO}_{8}$ dodecahedra that dominate the compressibility along the $a$-axis in zircon and the $c$-axis in scheelite.

The ambient-temperature pressure-volume equations of state of the zircon and scheelite phases have been fit with a second order Birch-Murgnahan EOS ${ }^{26,27}$ and are shown in Fig. 5 together with the volume data obtained after the ambient temperature and high pressure induced phase transition to scheelite. From the EOS fit we have obtained that the unit-cell volume at ambient pressure $V_{0}$ and the bulk modulus for both phases $K_{0}$ are: 316.4(7) $\AA^{3}$ and 158(13) GPa for zircon, and 280.2(8) $\AA^{3}$ and 158(17) GPa for 
scheelite. Both the bulk moduli obtained for the zircon and scheelite phases compare well with other zircon-type vanadates as $\mathrm{YVO}_{4}(130(3) \mathrm{GPa}$ in zircon and 138(8) GPa in scheelite $)^{5}$ and $\mathrm{SmVO}_{4}$ (129(4) GPa in zircon and 133(5) GPa in scheelite) ${ }^{28}$. In fact, this indicates that in zircon-type vanadates the bulk moduli of both zircon and scheelite-type phases are roughly similar. The compressibility of vanadates is expected to be dominated by the compressibility of the $\mathrm{RO}_{8}$ dodecahedra with the large volume collapse (usually around $10 \%$ ) of the zircon to scheelite phase transition being produced by a decrease of the voids in the structure instead of a volume reduction of the dodecahedra, i.e. an increase of the packing of the structure. This is confirmed when we compare the ambient-pressure dodecahedra volumes in both zircon and scheelite phases for $\mathrm{YVO}_{4}{ }^{5}, \mathrm{ErVO}_{4}$, and $\mathrm{SmVO}_{4}{ }^{28}: \quad V_{Y O 8}^{Z}=23.7(1) \AA^{3}, \quad V_{Y O 8}^{S}=23.8(2) \AA^{3}, \quad V_{E r O 8}^{Z}=23.4(1) \AA^{3}, \quad V_{\text {ErO8 }}^{S}=$ 23.1(2) $\AA^{3}, V_{S m 08}^{Z}=25.6(1) \AA^{3}$, and $V_{S m 08}^{S}=25.43(2) \AA^{3}$. This result raises the question about some reported bulk moduli for the scheelite phase of some vanadates as $\mathrm{EuVO}_{4}\left(K_{0}=195(8) \mathrm{GPa}^{29}\right.$ or $\mathrm{SmVO}_{4}$ with $K_{0}=256(12) \mathrm{GPa}$ instead of 133(5) GPa even when measured in almost identical conditions (methanol-ethanol or methanolethanol-water pressure media) but different runs ${ }^{28}$. In fact, the large differences obtained for the bulk modulus of scheelite-type $\mathrm{SmVO}_{4}$ in different runs and similar conditions indicate that the amount of sample might also have a large influence in order to precisely determine the lattice parameters after a $10 \%$ volume collapse in these vanadates. A good example is shown in our own experiment (Fig. 5) where the determination of the unit-cell volume from the diffractograms measured for the ambient-temperature and high-pressure induced scheelite gives rise to an apparently more compressible high-pressure phase with an unrealistic bulk modulus for the high pressure phase $40 \%$ lower. To avoid this problem, we have employed highly crystalline powder scheelite-type $\mathrm{ErVO}_{4}$ synthesized at high-pressure and high-temperature. Regarding the bulk modulus of zircon-type $\mathrm{ErVO}_{4}$ 
we have obtained a value that compares well with the previously estimated value from Brillouin scattering, $K_{0}=136(9) \mathrm{GPa}^{30}$.

\section{b. Phase diagram and thermal equation of state of zircon-type $\mathrm{ErVO}_{4}$}

In addition to the in-situ room temperature and ex-situ high temperature experiments presented above, we have performed in situ high-pressure experiments at two different temperatures: 370(10) K and 690(10) K. A selection of diffraction patterns taken at 690(10) K is shown in Fig. 6. At 690(10) K all the reflections correspond to the zircon-type phase up to 7.5(1) GPa when the 112 reflection from the scheelite phase emerges as the result of the onset of the phase transition. Considering that the phase transition occurs at 8.2(1) GPa at 290(10) K and at 7.5(1) GPa at 690(10) K we can conclude that the onset of the zircon-to-scheelite phase transition in $\mathrm{ErVO}_{4}$ slightly decreases with temperature. However, from our ex situ experiments we have observed that at $\sim 4 \mathrm{GPa}$ and $770(10) \mathrm{K}$ the transformation has already started. The proposed $P-T$ phase diagram is shown in Fig. 7. From these studies we have obtained the lattice parameters and volume along the three isotherms. The data are shown in Fig. 8. The fit to the thermal equation of state was carried out using EosFit- $7^{27}$ and considering the Berman equation ${ }^{31}$ where the change with temperature of the volumetric linear thermal expansion is calculated as $\alpha=\alpha_{0}+\alpha_{1}(T-293)$ and its change with pressure is disregarded ${ }^{27}$. Such a fit yields a value for the temperature independent thermal expansion at $293 \mathrm{~K}$ of $\alpha_{0}=0.9(2) \times 10^{-5} \mathrm{~K}^{-1}$ and a temperature derivative of the bulk modulus of $\mathrm{d} K_{0} / \mathrm{d} T=-3.8(2) \times 10^{-3} \mathrm{GPa} \mathrm{K}^{-1}$. The value of the temperature derivative of $K_{0}$ cannot be compared with other zircon-type vanadates due to the absence of this type of studies, but the value of the thermal expansion compares relatively well with other vanadates such as $\mathrm{NdVO}_{4}$ which expands with $\alpha_{0}=1.8(1) \times 10^{-5} \mathrm{~K}^{-1}$ according to the data reported by Vishnuvardhan et al. ${ }^{32}$. The larger value presented by $\mathrm{NdVO}_{4}$ can be understood since 
$\mathrm{NdVO}_{4}$ has longer and more ionic Nd-O bonds compared to Er-O bonds (around 9\% larger), and therefore a larger thermal expansion is expected.

As usual in most phase transitions, the zircon to scheelite phase transition is dominated by the occurrence of a denser packing that gives rise to a large volume collapse (11\% in $\mathrm{ErVO}_{4}$ as we have shown above). At high temperature zircon-type $\mathrm{ErVO}_{4}$ expands. At the zircon-to-scheelite phase transition the volume contracts. Thus, the zircon-scheelite boundary has a negative slope as we observe in Fig. 7. According to the Clausius-Clapeyron relationship, since the temperature derivative is negative, and the volume decreases at the transition, the negative slope indicates that entropy increases at the transition.

\section{c. Thermal expansion of zircon-type $\mathrm{ErVO}_{4}$}

The temperature dependence of the lattice parameters of $\mathrm{ErVO}_{4}$ was first reported by Hirano et al. $^{30}$ to show the large magnetoelastic coupling experienced with the structure when the magnetic transition occurs. From the reported neutron diffraction data from $13 \mathrm{~K}$ to ambient temperature ${ }^{22}$ and the four measured data points (110(3), 205(3), 298(3), and 395(3) K) of the present single crystal diffraction study, we have obtained the volumetric thermal expansion of $\mathrm{ErVO}_{4}$. The data are shown in Fig. 9 where the temperature variation of the thermal expansion is obtained from the quadratic least squares fit with all the available data points. To compare the thermal expansion obtained with these data with that deduced from the thermal EOS reported above we have considered only the temperature range above ambient temperature fitting it with a straight line. This yields a volumetric linear thermal expansion coefficient for $\mathrm{ErVO}_{4}$ of $1.4(2) \times 10^{-5} \mathrm{~K}^{-1}$ in good agreement, considering the uncertainties, with the value provided by the fit of the high-pressure, high-temperature data. 
In Table 3 we report the measurement, refinement, and crystallographic parameters obtained from our ambient pressure temperature dependent single-crystal XRD experiments. In the zircon structure only, the $y$ and $z$ coordinates of the O position are not constrained by symmetry. In the refinements we have refined anisotropically the Er and $\mathrm{V}$ position and isotropically the $\mathrm{O}$ site. As expected, the effect of increasing pressure (Table 2) is equivalent to lowering temperatures not only in the lattice parameters but also on the $\mathrm{O}$ coordinates. However, in terms of the thermal parameter $U_{\text {iso }}$ of $\mathrm{O}$, in the case of decreasing temperature it decreases from 0.0113(4) $\AA^{2}$ at $395 \mathrm{~K}$ to $0.0031(5) \AA^{2}$ at 110(3) K, while it barely increases under pressure.

\section{Conclusions}

The high-pressure zircon to scheelite phase transition of $\mathrm{ErVO}_{4}$ has been shown to be unattainable with single crystal x-ray diffraction with the single crystal collapsing or even with powder x-ray diffraction at ambient temperature with yielding unrealistic unit-cell volume dependence with pressure. A systematic study of the synthesis conditions at 4 GPa has provided us with the best temperature (973 K) to obtain almost phase pure (94 wt. \%) scheelite phases. The use of higher temperatures entails the reduction of $\mathrm{V}^{5+}$ forming perovskite-type $\mathrm{ErVO}_{3}$. The study of both phases with high-pressure and hightemperature x-ray diffraction has yielded bulk moduli of $K_{0}=158(13)$ GPa and 158(17) GPa for the zircon and scheelite phases, and a temperature derivative for the zircon phase of $\mathrm{d} K_{0} / \mathrm{dT}=-3.8(2) \times 10^{-3} \mathrm{GPaK}^{-1}$, according to Berman model. The similarity of the bulk moduli obtained for both phases of $\mathrm{EVO}_{4}$ indicate that the compressibility is governed by the $\mathrm{RO}_{8}$ dodecahedra and the volume of $\mathrm{RO}_{8}$ does not decrease appreciably at the phase transition despite the large unit-cell volume collapse. Finally, we have determined 
for the zircon phase the volumetric thermal expansion $\alpha_{0}$ from the thermal equation of state with Berman model $\left(0.9(2) \times 10^{-5} \mathrm{~K}^{-1}\right)$ and from single-crystal $\mathrm{x}$-ray diffraction at different temperatures $\left(1.4(2) \times 10^{-5} \mathrm{~K}^{-1}\right.$ ) and they agree with each other within limit of uncertainty and also with previous reported data in other vanadates.

\section{Acknowledgements}

J.R.-F. and D.S.-P. thank the Spanish Ministry of Economy and Competitiveness (MINECO) for the Juan de la Cierva (IJCI-2014-20513) and Ramón y Cajal (RyC-201415643) Programs. This work was supported by the MINECO with the project MAT201675586-C4-1-P/2-P. ALBA-CELLS synchrotron is acknowledged for granting beamtime at the MSPD beamline under projects 2016081784 and 2017022036. Parts of this research were carried out at the light source PETRA III at DESY (Project No. I-20160082 EC), a member of the Helmholtz Association (HGF). British Crown Owned Copyright 2018/AWE. Published with permission of the Controller of Her Britannic Majesty’s Stationery Office.

\section{References}

[1] Shafi, S. P.; Kotyk, M. W.; Cranswick, L. M. D.; Michaelis, V. K.; Kroeker, S.; Bieringer, M. In Situ Powder X-ray Diffraction, Synthesis, and Magnetic Properties of the Defect Zircon Structure $\mathrm{ScVO}_{4-\mathrm{x}}$. Inorg. Chem. 2009, 48, 10553.

[2] Huang, Z.; Zhang, L.; Pan, W. Synthesis, Lattice Dynamics, and Mechanical Properties of a High-Pressure Scheelite Phase of RVO4. Inorg. Chem. 2012, 51, 11235 and references therein.

[3] Khan, A. F.; Haranath, D.; Yadav, R.; Singh, S.; Chawla S.; Dutta, V. Controlled surface distribution and luminescence of $\mathrm{YVO}_{4}: \mathrm{Eu}^{3+}$ nanophosphor layers. Appl. Phys. Lett. 2008, 93073103.

[4] Errandonea, D.; Garg, A. B. Recent progress on the characterization of the highpressure behaviour of $\mathrm{AVO}_{4}$ orthovanadates. Prog. Mater. Sci. 2018, 97, 123. 
[5] Wang, X.; Loa, I.; Syassen, K.; Hanfland, M.; Ferrand, B. Structural properties of the zircon- and scheelite-type phases of $\mathrm{YVO}_{4}$ at high pressure. Phys. Rev. B 2009, 70, 064109.

[6] Panchal, V.; López-Moreno, S.; Santamaría-Pérez, D.; Errandonea, D.; Manjón, F. J.; Rodríguez-Hernández, P.; Muñoz, A.; Achary, S. N.; Tyagi, A. K.; Zircon to monazite phase transition in $\mathrm{CeVO}_{4}$ : X-ray diffraction and Raman-scattering measurements. Phys. Rev. B. 2011, 84, 024111.

[7] Range K. -J.; Meister, H. ErVO 4 -II, a Scheelite-Type High-Pressure Modification of Erbium Orthovanadate. Acta Cryst. C 1990, 46, 1093.

[8] Shin-ike, T.; Adachi, G.; Shiokawa, J.; Shimada, M.; Koizumi, M. Studies on the high-pressure reaction of $\mathrm{Er}_{2} \mathrm{O}_{3}$ and $\mathrm{VO}_{2}$. Mat. Res. Bull. 1979, 14, 1323.

[9] Capobianco, J. A.; Kabro, P.; Ermeneux, F. S.; Moncorgé, R.; Bettinelli, M.; Cavalli, E.; Optical spectroscopy, fluorescence dynamics and crystal-field analysis of $\mathrm{Er}^{3+}$ in $\mathrm{YVO}_{4}$. Chemical Physics 1997, 214, 329.

[10] Larson, A. C.; Von Dreele, R. B. General Structure Analysis System (GSAS), Los Alamos National Laboratory Report LAUR. 2000, 86-748.

[11] Toby, B. H. EXPGUI, a graphical user interface for GSAS, J. Appl. Cryst. 2001, 34, 210.

[12] Mao, H. K.; Xu, J.; Bell, P. M. Calibration of the ruby pressure gauge to $800 \mathrm{kbar}$ under quasi-hydrostatic conditions. J. Geophys. Res. 1986, 91, 4673.

[13] Santamaria-Perez, D.; Mukherjee, G. D.; Schwager, B.; Boehler, R. Phys. Rev. B 2010, 81, 214101.

[14] Klotz, S.; Chervin, J. C.; Munsch, P.; Le Marchand. G. Hydrostatic Limits of 11 Pressure Transmitting Media. J. Phys. D: Appl. Phys. 2009, 42, 075413.

[15] Rothkirch, A.; Gatta, G. D.; Meyer, M.; Merkel, S.; Merlini, M.; Liermann, H. P. Single-crystal diffraction at the Extreme Conditions beamline P02.2: procedure for collecting and analyzing high-pressure single-crystal data. J. Synchrotron Radiat. 2013, 20, 711 .

[16] Agilent, CRYSALIS ${ }^{P r o}$ software system, version 1.171.36.28, Agilent Technologies UK Ltd., Oxford, UK, 2013.

[17] Sheldrick, G. M. A short history of SHELX. Acta Crystallogr., Sect. A. 2008, 64, 112. 
[18] Angel, R. J.; Bujak, A.; Zhao, J.; Gatta, G. D.; Jacobsen, S. D. Effective hydrostatic limits of pressure media for high-pressure crystallographic studies. J. Appl. Crys. 2007, 40, 26.

[19] Holland, T. J. B.; Redfern, S. A. T. Unit cell refinement from powder diffraction data: the use of regression diagnostics. Mineralogical Magazine. 1997, 61, 65.

[20] Stinton, G. W.; MacLeod, S. G.; Cynn, H.; Errandonea, D.; Evans, W. J.; Proctor, J. E.; Meng, Y.; McMahon, M. I. Equation of state and high-pressure/high-temperature phase diagram of magnesium. Phys. Rev. B. 2014, 90, 134105.

[21] Santamaría-Pérez, D.; Marqueño, T.; MacLeod, S.; Ruiz-Fuertes, J.; Daisenberger, D.; Chuliá-Jordan, R.; Errandonea, D.; Jordá, J. L.; Rey, F.; McGuire, C.; Mahkluf, A.; Kavner, A.; Popescu, C. Structural Evolution of $\mathrm{CO}_{2}$-Filled Pure Silica LTA Zeolite under High-Pressure High-Temperature Conditions. Chem. Mater. 2017, 29, 4502.

[22] Dorogokupets P. I.; Dewaele, A. Equations of state of $\mathrm{MgO}, \mathrm{Au}, \mathrm{Pt}, \mathrm{NaCl}-\mathrm{B} 1$, and NaCl-B2: Internally consistent high-temperature pressure scales. High Pressure Res. 2007, 27, 431.

[23] Tojo, T.; Zhang, Q.; Saito, F. Mechanochemical synthesis of rare earth orthovanadates from $\mathrm{R}_{2} \mathrm{O}_{3}\left(\mathrm{R}=\right.$ rare earth elements) and $\mathrm{V}_{2} \mathrm{O}_{5}$ powders J. Alloy Compd. 2007, 427, 219.

[24] J. A. Baglio J. A.; Sovers, O. J. Crystal structures of the rare-earth orthovanadates. J. Sol. State Chem. 1971, 3, 458.

[25] Gomis, O.; Lavina, B.; Rodríguez-Hernández, P.; Muñoz, A.; Errandonea, D.; Bettinelli, M. High-pressure structural, elastic, and thermodynamic properties of zircontype $\mathrm{HoPO}_{4}$ and $\mathrm{TmPO}_{4}$. J. Phys.: Condens. Matter 2017, 29, 095401.

[26] Birch, F. Elasticity and constitution of the Earth's interior. J. Geophys. Res. 1952, $57,227$.

[27] Angel, R. J.; González-Platas, J.; Alvaro, M. EosFit-7 and a Fortran module (library) for equation of state calculations, Zeitchrift für Kristallographie 2014, 229, 405.

[28] Popescu, C.; Garg, A. B.; Errandonea, D.; Sans, J. A.; Rodríguez-Hernández, P.; Radescu, S.; Muñoz, Achary, S. N.; Tyagi, A. K. Pressure-induced phase transformation in zircon-type orthovanadate $\mathrm{SmVO}_{4}$ from experiment and theory. J. Phys.: Condens. Matter 2016, 28, 035402.

[29] Garg A. B.; Errandonea, D. High-pressure powder x-ray diffraction study of EuVO. J. Sol. State Chem. 2015, 226, 147. 
[30] Hirano, Y.; Skanthakumar, S.; Loong, C. -K.; Wakabayashi, N.; Boatner, L. A. Lattice and magnetic properties of $\mathrm{ErVO}_{4}$ and $\mathrm{ErPO}_{4}$. Phys. Rev. B 2002, 66, 024424.

[31] Berman, R. G. Internally-consistent thermodynamic data for minerals in the system. J. Petrology 1988, 29, 445.

[32] Vishnuvardhan Reddy, C.; Kistaiah, P.; Satyanarayana Murthy, K. X-Ray study of the thermal expansion anisotropy in neodymium vanadate. J. Alloys Compd. 1995, 218, 4. 

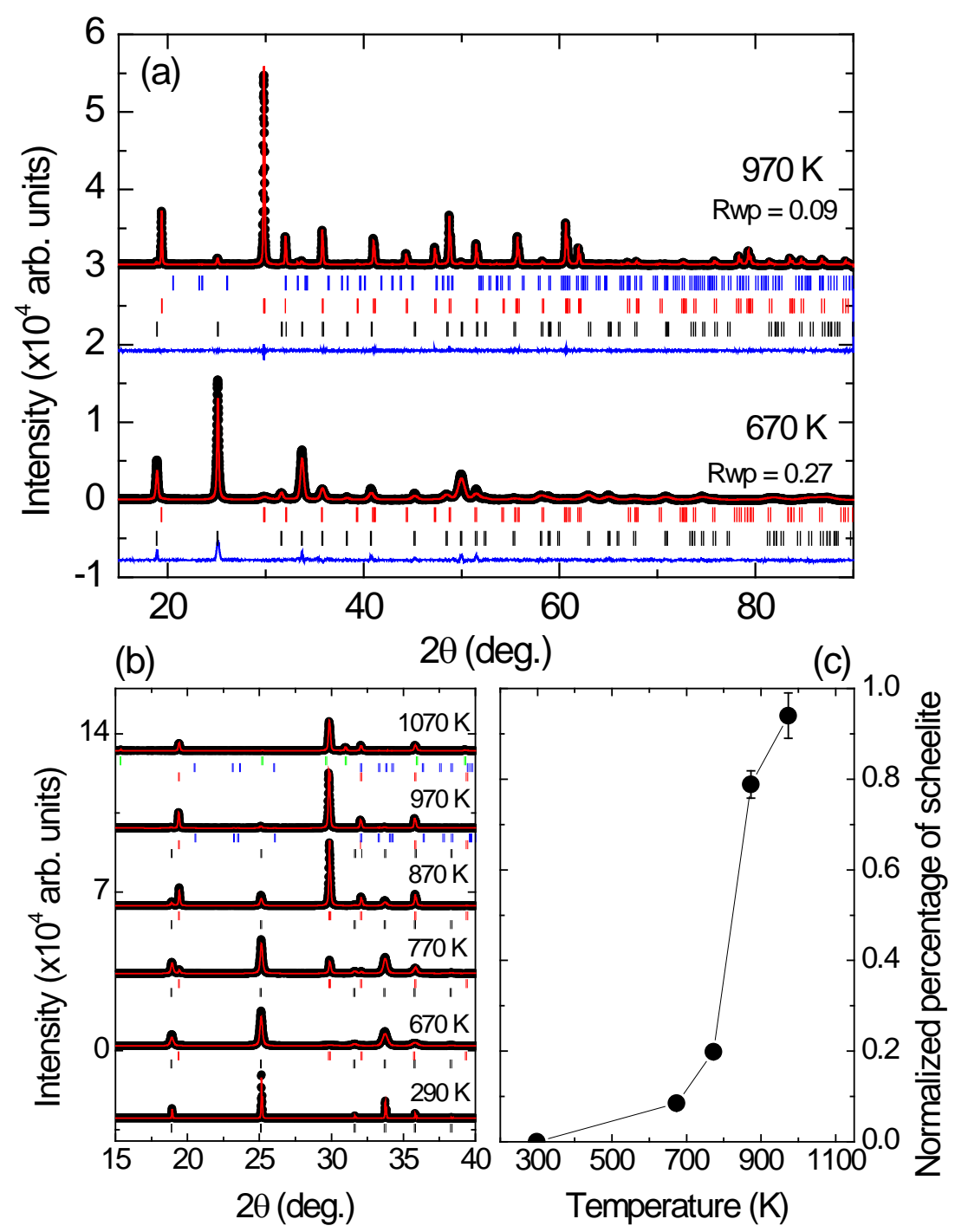

Figure 1. X-ray patterns obtained with the quenched product after submitting zircon-type $\mathrm{ErVO}_{4}$ at $4 \mathrm{GPa}$ and different temperatures. The complete diffractogram of the product obtained after 670(10) and 970(10) K (a) as well as the low-2 $\theta$ angle range at all the synthesis temperatures (b) are shown. The black, red, blue, and green ticks indicate the reflections of the zircon-type $\mathrm{ErVO}_{4}$, scheelite-type $\mathrm{ErVO}_{4}$, reduced perovskite-type $\mathrm{ErVO}_{3}$, and pyroclore-type $\mathrm{Er}_{2} \mathrm{~V}_{2} \mathrm{O}_{7}$. Dots are the experimental data and the continuous red lines are the rietveld fits. The blue continuous lines are the experimental to theory difference. (c) Synthesis temperature evolution of the normalized percentage of scheelite-type $\mathrm{ErVO}_{4}$ [Scheelite wt. \%/(Scheelite wt. \% + Zircon wt. \%)] obtained after the Rietveld refinements. 
Table 1. Lattice parameters and atomic coordinates of zircon-type and scheelite-type $\mathrm{ErVO}_{4}$ at ambient pressure as obtained with powder $\mathrm{x}$-ray diffraction from our syntheses. In the case of the scheelite the atomic coordinates were not refined using those published in Ref. [4].

\begin{tabular}{ccccc}
\hline \hline & $\begin{array}{c}\text { Zircon } \\
\text { This work }\end{array}$ & $\begin{array}{c}\text { Zircon } \\
\text { Baglio and Solvers[18] }\end{array}$ & $\begin{array}{c}\text { Scheelite } \\
\text { This work }\end{array}$ & $\begin{array}{c}\text { Scheelite } \\
\text { Range [4] }\end{array}$ \\
\hline \hline Space Group & I4 $/$ amd & I4 $/$ amd & $I 4_{1} / a$ & $I 4_{1} / a$ \\
\hline \hline$a(\AA)$ & $7.09595(3)$ & $7.09570(10)$ & $5.01466(3)$ & $5.003(1)$ \\
$c(\AA)$ & $6.27105(3)$ & $6.27290(10)$ & $11.17009(10)$ & $11.143(2)$ \\
O (x) & 0 & 0 & 0.1460 & $0.1460(6)$ \\
$\mathrm{O}(y)$ & $0.437(1)$ & $0.4349(1)$ & 0.5050 & $0.5050(6)$ \\
$\mathrm{O}(z)$ & $0.200(1)$ & $0.2004(1)$ & 0.2054 & $0.2054(3)$ \\
\hline \hline
\end{tabular}



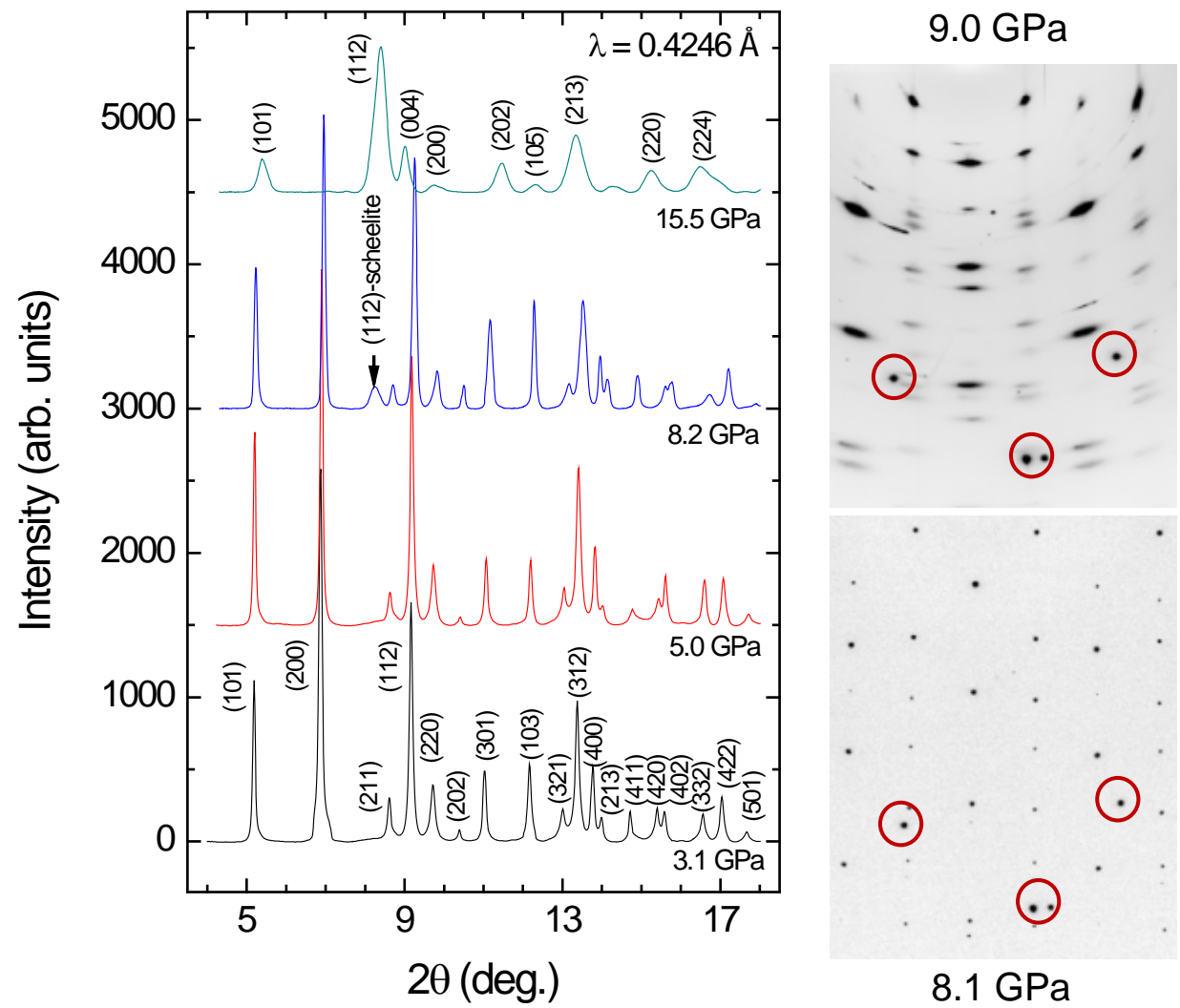

Figure 2. (Left) Ambient temperature x-ray diffraction patterns of zircon-type $\mathrm{ErVO}_{4}$ collected at different pressures. The appearance of the 112 reflection of the scheelite phase at 8.2(1) GPa set the onset of the phase transition at ambient temperature. The phase transition is completed at 15.5(2) GPa when the reflections are broad. (Right) Same section of a $20^{\circ}-\omega$ scan just below (8.1(1) GPa) and just above (9.0(1) GPa) showing the loss of crystallinity of the sample. While the reflections from the diamonds of the culets (circled) remain rounded, the reflections from the sample broaden and split as indicative of the breaking of the single crystal due to the large volume collapse in the phase transition. 


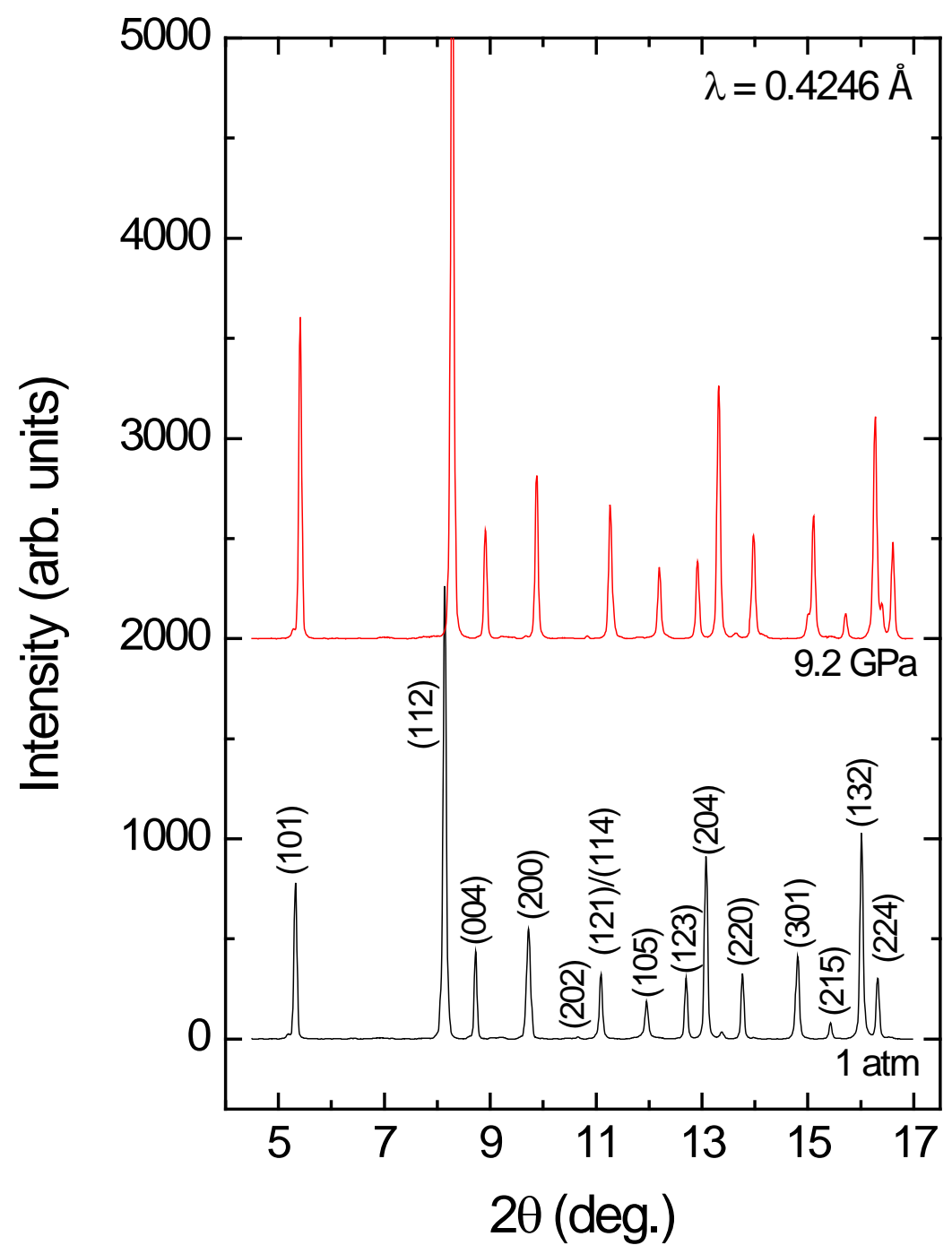

Figure 3. Ambient temperature x-ray diffraction patterns of scheelite-type $\mathrm{ErVO}_{4}$ collected at different pressures. 
Table 2. Lattice parameters, atomic coordinates for the $\mathrm{O}$ atom, isotropic displacement parameters, collection details, and refinement parameters of zircon-type $\mathrm{ErVO}_{4}$ at 6.4 and 8.1 GPa.

\begin{tabular}{ccc}
\hline$P(\mathrm{GPa})$ & $6.4(1)$ & $8.1(1)$ \\
\hline \hline$a(\AA)$ & $6.98398(12)$ & $6.95744(12)$ \\
$c(\AA)$ & $6.20727(12)$ & $6.19219(13)$ \\
O $(y)$ & $0.4360(5)$ & $0.4366(6)$ \\
O $(z)$ & $0.1997(5)$ & $0.1993(5)$ \\
Oxygen $\mathrm{U}_{\text {iso }}$ & $0.100(5)$ & $0.0102(6)$ \\
Measured refl. & 829 & 824 \\
Unique refl. & 181 & 178 \\
Refined param. & 9 & 9 \\
Rint & 0.0384 & 0.0311 \\
R1 & 0.0352 & 0.0373 \\
wR2 & 0.0836 & 0.0892 \\
GooF & 1.267 & 1.232 \\
\hline \hline
\end{tabular}



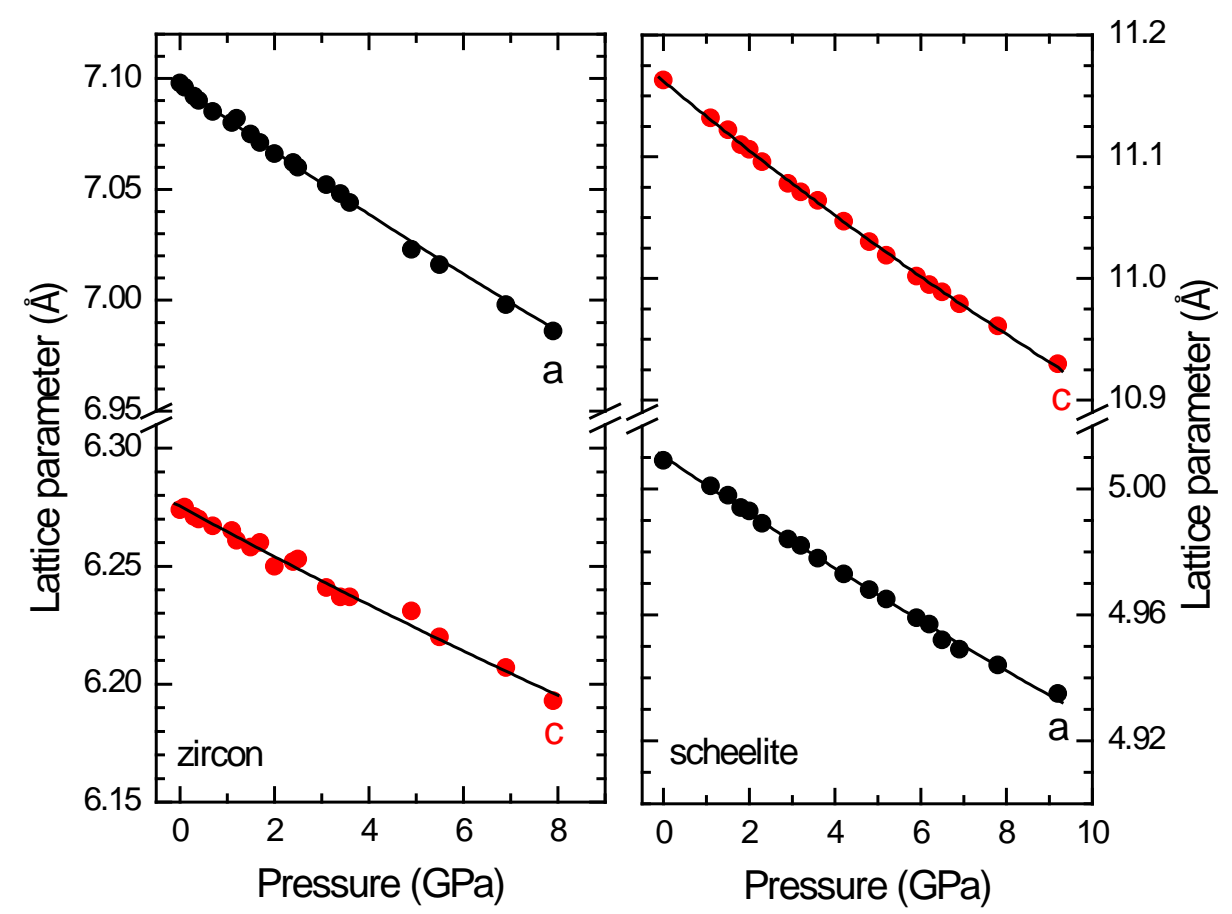

Figure 4. Pressure dependence of the lattice parameters of zircon and scheelite-type ErVO$_{4}$. The dots are experimental data and the lines are fits to a second-order BirchMurnaghan equations of state assuming cubic lattices. 


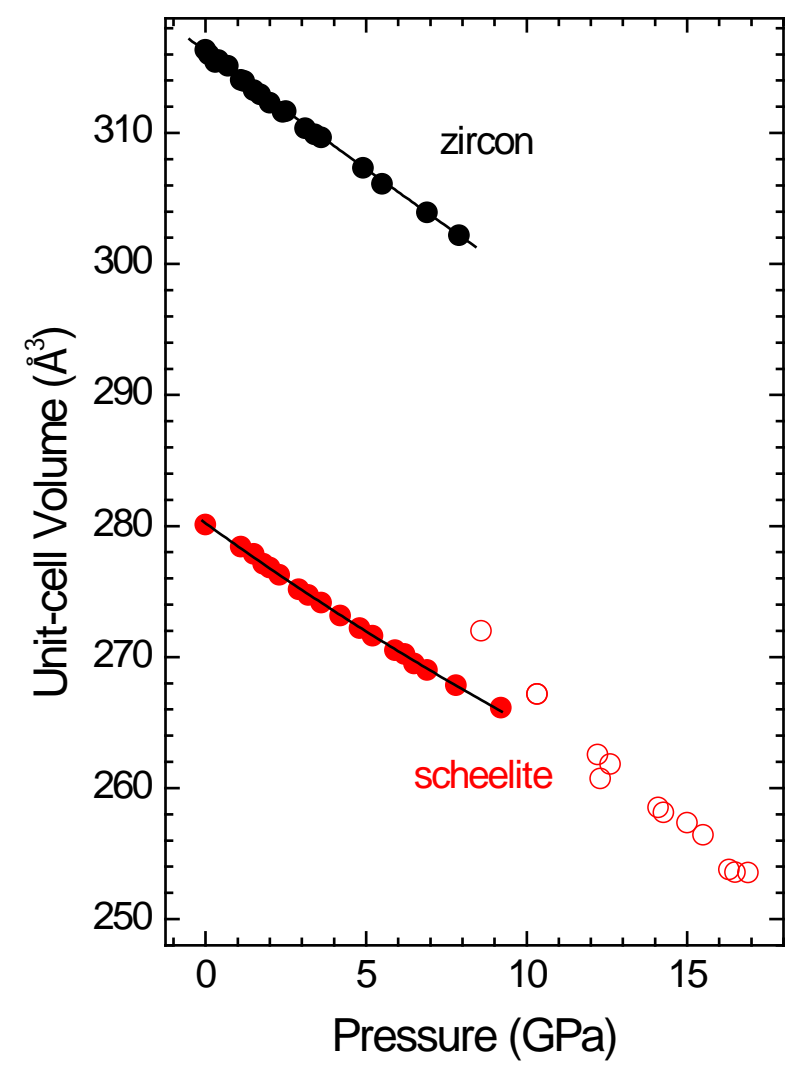

Figure 5. Ambient temperature equation of state of zircon-type and Scheelite-type $\mathrm{ErVO}_{4}$. Dots are the experimental points and the continuous lines are the fits according to a second-order Birch-Murnaghan equation of state. Empty dots are volume data obtained for scheelite after the phase transition at ambient temperature and 8.1(1) GPa of zircontype $\mathrm{ErVO}_{4}$. 


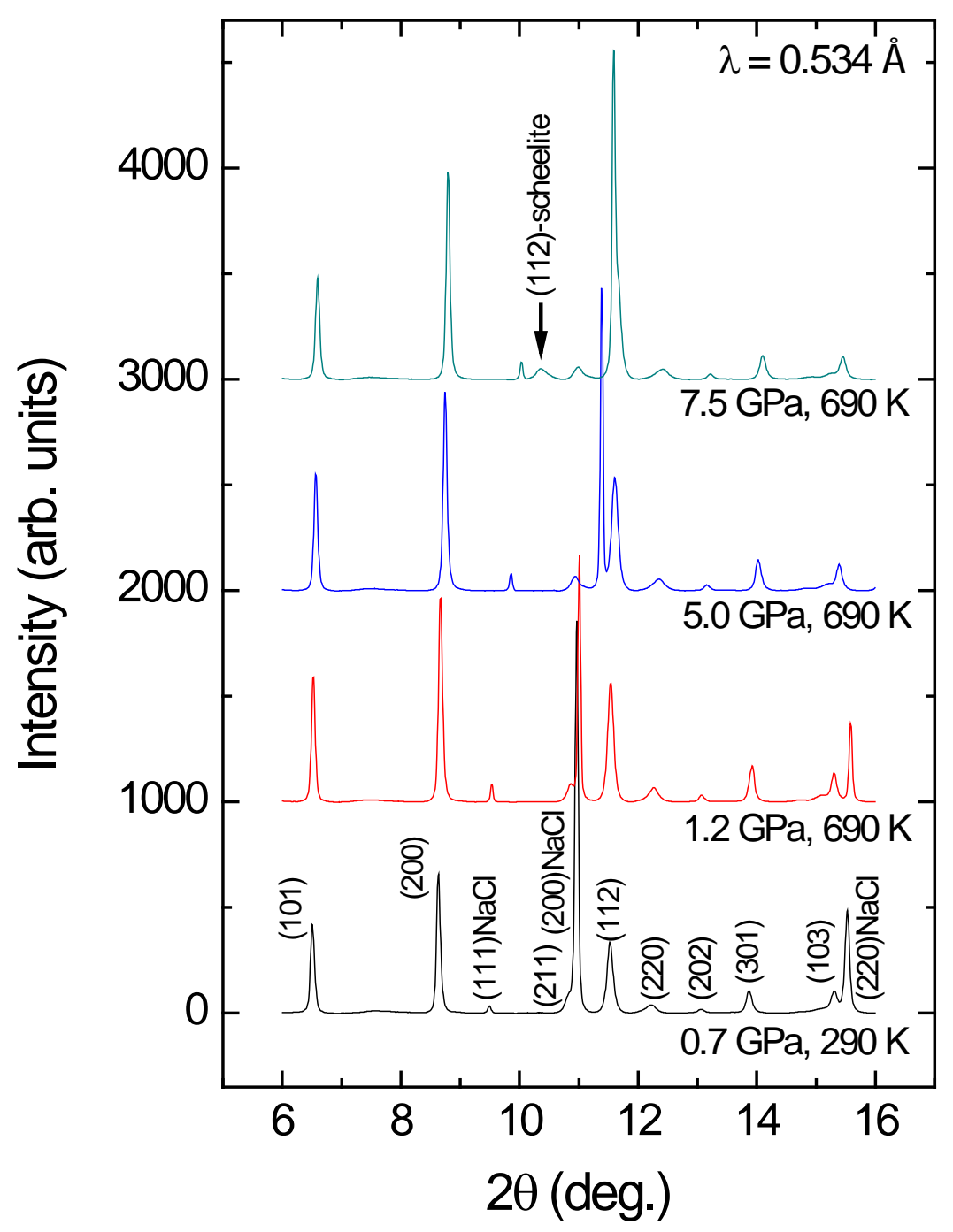

Figure 6. X-ray diffraction patterns of zircon-type $\mathrm{ErVO}_{4}$ collected at different pressures following the 690(10) $\mathrm{K}$ isotherm. The reflections from the sample and from the pressure calibrant $\mathrm{NaCl}$ are indicated. The onset of the phase transition to scheelite is indicated. 


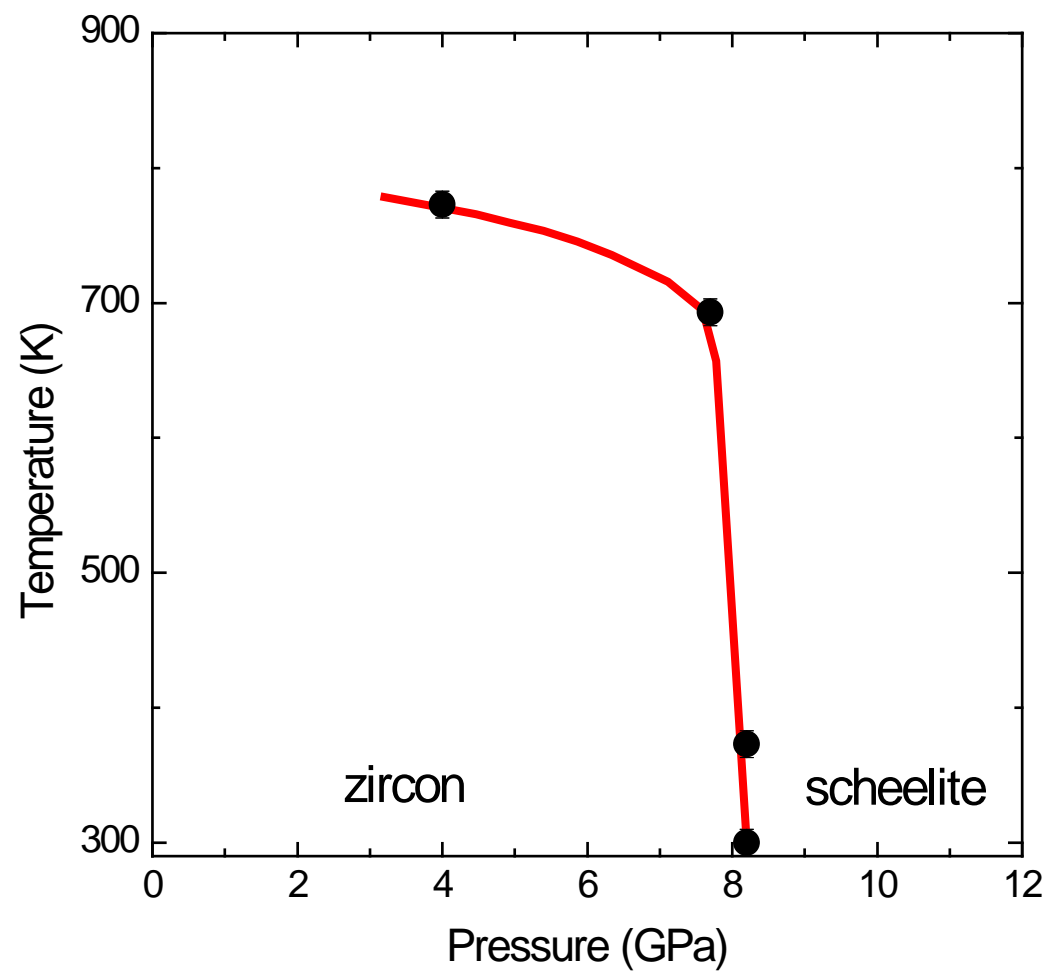

Figure 7. Zircon to scheelite phase boundary of $\mathrm{ErVO}_{4}$. The point at $\sim 4 \mathrm{GPa}$ corresponds to an ex situ point. The next three points are obtained in situ. The line is a guide for the eye. 


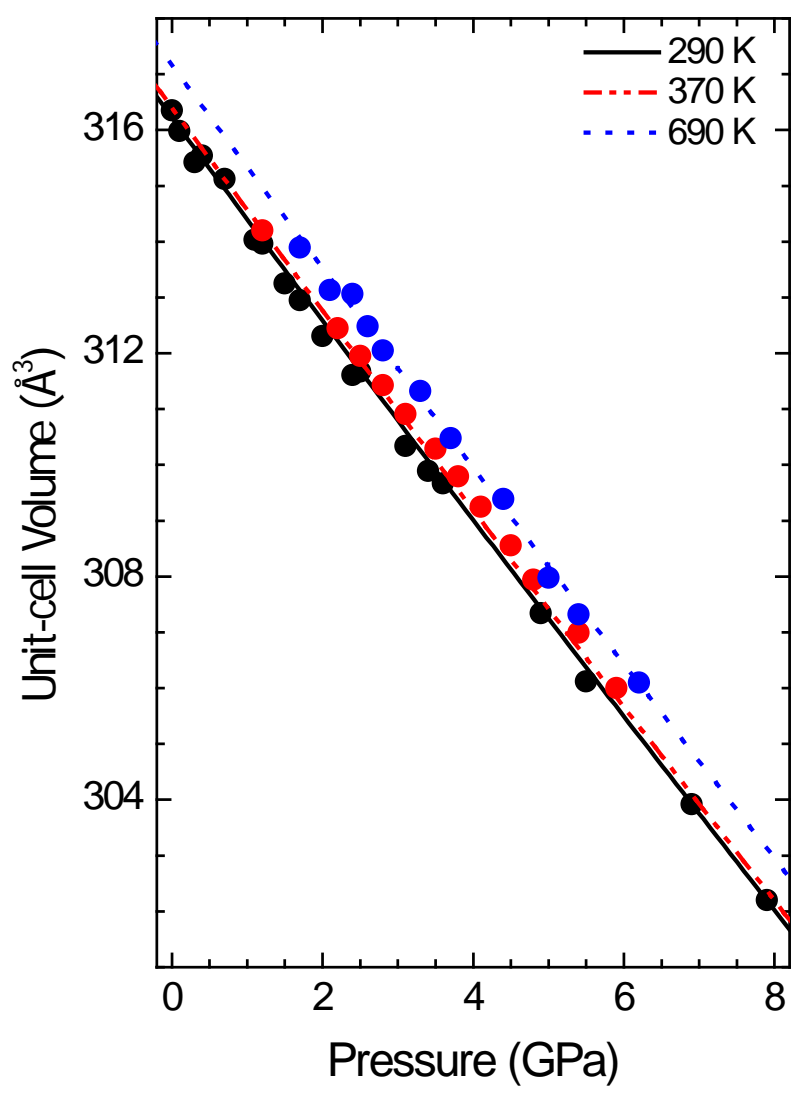

Figure 8. PVT equation of state (EOS) of zircon-type $\mathrm{ErVO}_{4}$. Data corresponding to three isotherms are shown. The symbols that correspond to the experiments are fit all together with a second order Birch-Murnaghan EOS and the Berman equation. 


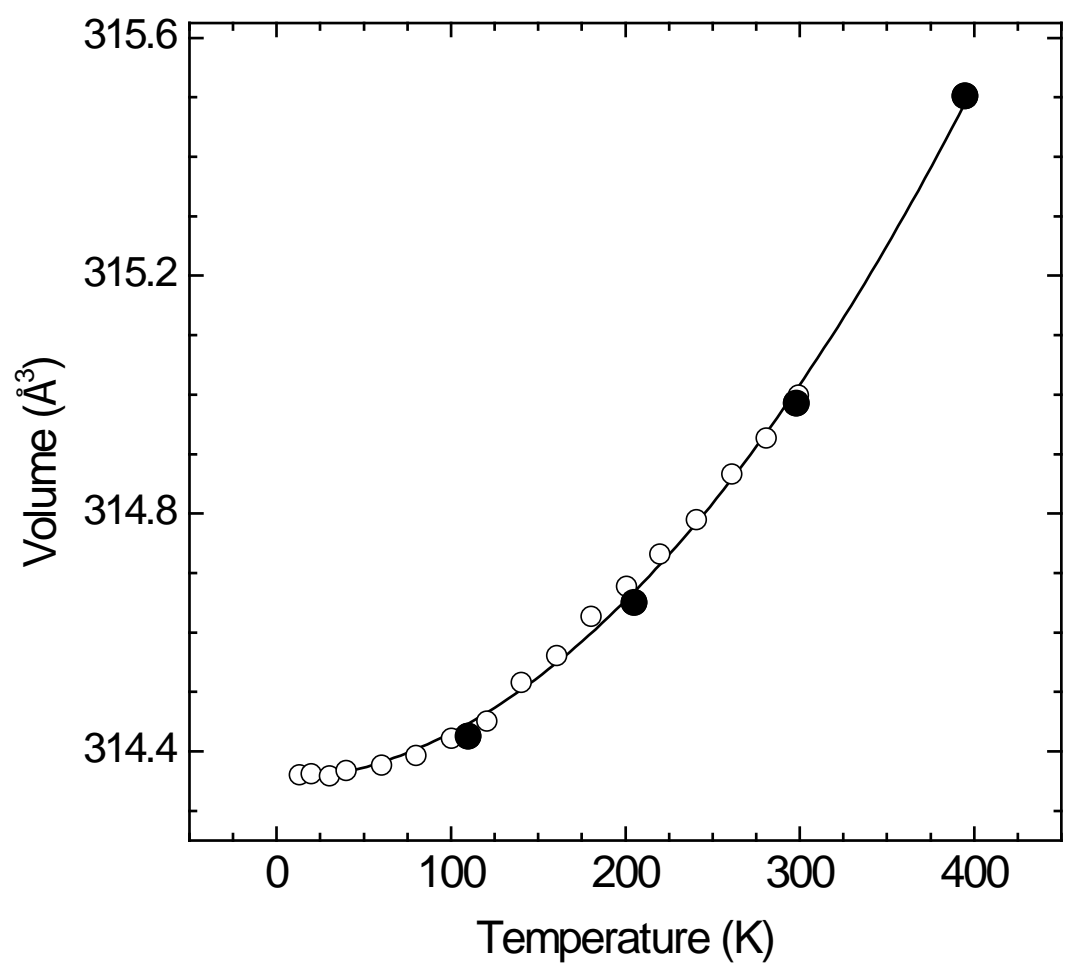

Figure 9. Temperature dependence of the unit-cell volume of zircon-type ErVO4. Empty dots are the volume values calculated from the reported lattice parameters extracted from Ref. [30] and the filled dots are data obtained from our single crystal XRD experiment. The continuous line is a guide for the eye. 
Table 3. Lattice parameters, atomic coordinates for the $\mathrm{O}$ atom, isotropic displacement parameters, collection details, and refinement parameters of zircon-type $\mathrm{ErVO}_{4}$ at 110(3), 205(3), 298(3), and 395(3) K.

\begin{tabular}{ccccc}
\hline \hline$T(\mathrm{~K})$ & $110(3)$ & $205(3)$ & $298(3)$ & $395(3)$ \\
\hline \hline$a(\AA)$ & $7.08956(11)$ & $7.08874(12)$ & $7.0892(3)$ & $7.09366(11)$ \\
$c(\AA)$ & $6.2557(2)$ & $6.2602(3)$ & $6.2665(4)$ & $6.2699(3)$ \\
O $(y)$ & $0.4354(4)$ & $0.4353(4)$ & $0.4351(4)$ & $0.4350(3)$ \\
O $(z)$ & $0.1994(4)$ & $0.1999(5)$ & $0.2002(5)$ & $0.2001(4)$ \\
Oxygen Uiso & $0.0031(5)$ & $0.0064(4)$ & $0.0088(5)$ & $0.0113(4)$ \\
Measured refl. & 1409 & 709 & 718 & 715 \\
Unique refl. & 210 & 210 & 210 & 208 \\
Refined param. & 9 & 9 & 9 & 9 \\
Rint & 0.0138 & 0.0138 & 0.0209 & 0.0151 \\
R1 & 0.0225 & 0.0178 & 0.0223 & 0.0201 \\
wR2 & 0.0671 & 0.0493 & 0.0619 & 0.0641 \\
GooF & 0.769 & 1.193 & 1.163 & 0.674 \\
\hline \hline
\end{tabular}




\section{Zircon to scheelite transformation of $\mathrm{ErVO}_{4}$ at $4 \mathrm{GPa}$}
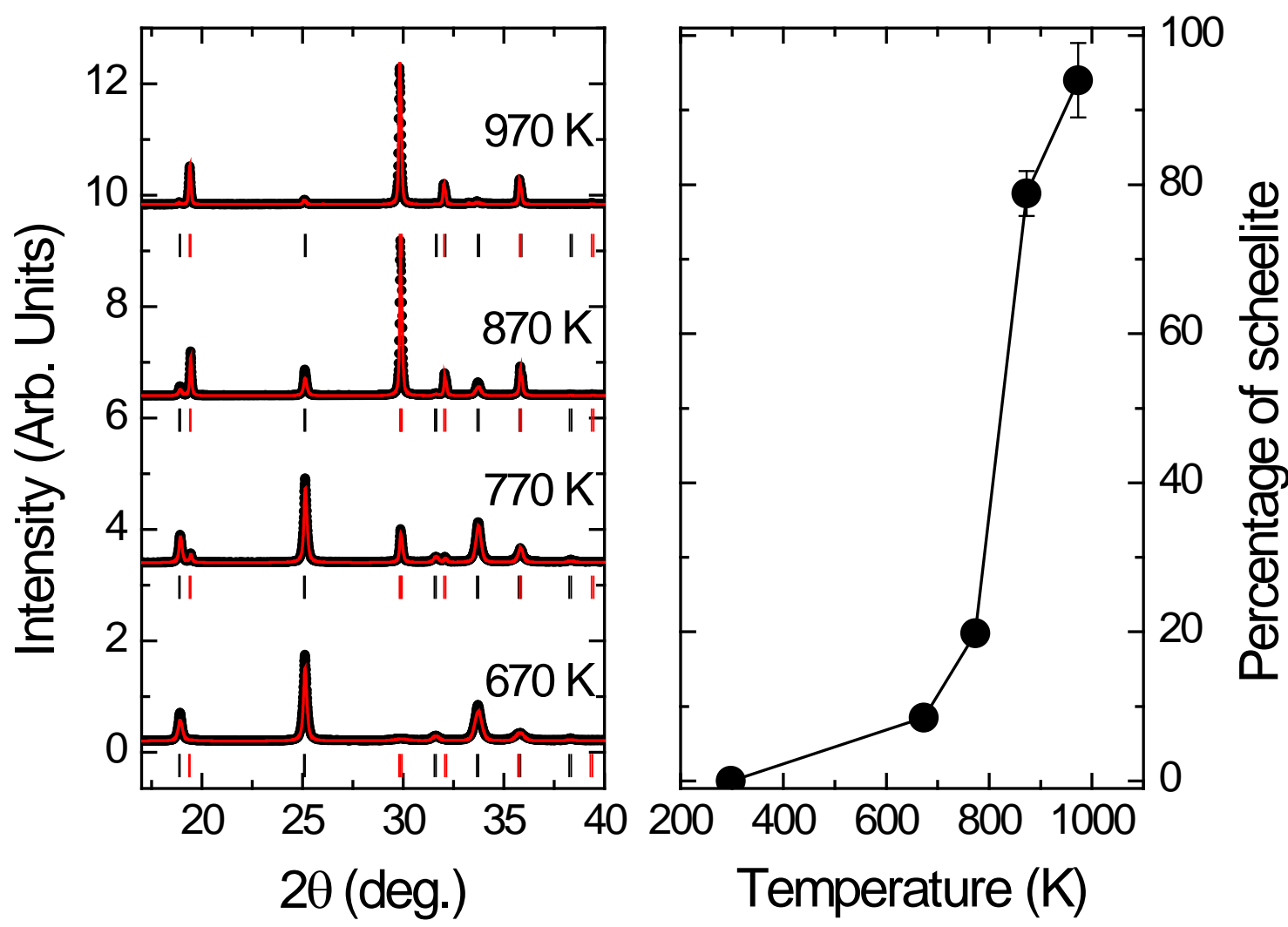

Figure for Table of Contents (TOC): The effect of temperature on the zircon to scheelite transformation of $\mathrm{ErVO}_{4}$ has been found to be critical to obtaining crystalline scheelite-type $\mathrm{ErVO}_{4}$; a necessary step to acquiring a reliable bulk modulus of this highpressure phase of zircon vanadates. Our studies indicate that above 1070(10) K and 4 GPa the $\mathrm{V}^{5+}$ of $\mathrm{ErVO}_{4}$ reduces to $\mathrm{V}^{3+}$ and $\mathrm{V}^{4+}$. 